\title{
Agentes globais e esfera local: o pólo automobilístico de Gravataí'
}

\section{Resumo}

O artigo tenta discutir aspectos das relações global-local, focalizando o processo de formação e desenvolvimento do pólo automobilístico de Gravataí e suas implicações sociais no âmbito das relações de trabalho e emprego em empresas locais. Ao reconhecer a recente formação do sistema global, supõe-se que a presença de agentes globais em contextos locais tenderia a criar novas dinâmicas sociais que dependeriam de articulações específicas entre conjunturas econômico-institucionais, níveis e tipos de recursos econômicos e sociais disponíveis, e estratégias mobilizadas pelos agentes sociais. Os agentes globais imporiam novas referências competitivas e tecnológicas aos agentes locais, que se achariam, com frequência, despreparados para acompanhar tais exigências. Por outro lado, poderiam ser criadas, com diferentes configurações, chances de acesso a capitais, mercados, tecnologias e conhecimentos, estimulando mudanças nas relações de trabalho e emprego na esfera local. A assimetria nas relações de poder econômico não impediria a reação dos agentes locais, nas possibilidades de seus recursos e nos horizontes de seus valores, às novas regras e condições do sistema internacional. A relação global-local teria, portanto, implicações distintas entre os agentes sociais.

Palavras-chave: Indústria automobilística. Relações de trabalho e emprego. Cadeia produtiva. Desenvolvimento regional. Globalização.

\footnotetext{
* Professor no Programa de Pós-Graduação em Sociologia e no Departamento de Sociologia da Universidade Federal do Rio Grande do Sul. Licenciado em Ciências Sociais, Mestre em Sociologia e Doutor em Sociologia pela UFRGS.

$1 \mathrm{O}$ artigo reúne aspectos da tese defendida no Programa de Pós-Graduação em Sociologia, UFRGS, 2006. Agradecimentos às contribuições dos professores Sônia Guimarães (orientadora), José Ricardo Ramalho, Anita Brumer, Valmíria Piccinini e Cínara Rosenfield, que constituíram a Banca Examinadora.
} 


\section{Introdução}

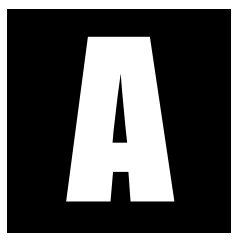

questão das relações global-local tem sido vivamente debatida na sociologia brasileira e internacional, sobressaindo-se a literatura em torno da ideia de sistema mundial e estudos que reconhecem a recente configuração de um sistema global. O presente artigo tenta discutir essa questão, apoiando-se em evidências relativas à experiência do pólo automobilístico de Gravataí, na primeira metade dos anos 2000.

A perspectiva do sistema mundial situa as relações de troca internacional no contexto de continuidade de processos de dominação entre países centrais e periféricos do sistema capitalista. A mundialização do capital representaria a nova face do imperialismo de países e atores econômicos dominantes, concebendo-se a possibilidade de processos autônomos de desenvolvimento nacional. Países e corporações multinacionais tenderiam a submeter atores nacionais e locais aos seus interesses, reforçando e reproduzindo sua hegemonia no sistema mundial (ARRIGHI, 1997; WALLERSTEIN, 2000).

A perspectiva do sistema global identifica, em oposição às teses em favor de uma suposta continuidade nas relações de troca internacionais, a recente emergência de uma esfera transnacional de poder político e econômico - sustentada pela revolução das tecnologias da informação e comunicação - que escaparia ao controle dos agentes nacionais. O recente sistema global distinguir-se-ia pelo grau de mobilidade e interdependência entre os agentes sociais, assim como pela ausência de um centro irradiador de poder. As novas relações de troca, comunicação e poder internacionais exigiriam mudanças nas estratégias dos agentes e instituições nacionais, tendo em vista a sua integração ao sistema global. Desse prisma, as relações entre agentes globais e locais não seriam unilaterais. Por outro lado, a cooperação entre os mesmos tornar-se-ia problemática 
porque a mobilidade dos agentes na esfera transnacional permitir-lhes-ia escapar às instituições e regulamentos no âmbito nacional ou subnacional. O provável seriam relações marcadas por novos tipos de conflitos e reações dos agentes, buscando-se novas formas de governança (BECK, 1999; THERBORN, 2000).

Independente da perspectiva do analista, há certo consenso no debate sociológico atual de que processos globais produziriam distintos efeitos sobre países e grupos sociais, tanto pelo desequilíbrio nas relações de poder internacionais quanto por escolhas equivocadas ou acertadas dos agentes sociais, relacionadas a conjunturas e valores internos aos países. O debate sociológico tem reagido a supostas homogeneidades e determinações que privilegiam fatores de ordem econômica no problema da integração do local ao global, mostrando a ocorrência de diferentes trajetórias e seus condicionantes não apenas técnico-econômicos como também político-sociais (HARRINSON; HUNTINGTON, 2002). Discussões acaloradas sobre a conveniência ou não da integração do país ao sistema global em voga nos anos 1990, cedem o passo para debates relativos às formas de integração e seus impasses e dilemas nos anos 2000 (ERNEST; KIM, 2001; HUMPHREY, 2001; SCHMITZ, 2000; STORPER; CHEN; PAOLIS, 2000), destacando-se as inter-relações entre recursos objetivamente distribuídos; valores, crenças e capacidade de escolha dos agentes; e processos de mudança social. O debate atual busca definir, com maior precisão, o processo de globalização.

Ao reconhecer a recente formação do sistema global, supõe-se, no presente artigo, que a presença de agentes globais em contextos locais tenderia a criar novas dinâmicas sociais que dependeriam de articulações específicas entre conjunturas econômico-institucionais, níveis e tipos de recursos econômicos e sociais disponíveis, e estratégias mobilizadas pelos agentes sociais. Os agentes globais imporiam novas referências competi- 
tivas e tecnológicas aos agentes locais, que se achariam, com frequência, despreparados para acompanhar tais exigências. Por outro lado, poderiam ser criadas, com diferentes configurações, chances de acesso a capitais, mercados, tecnologias e conhecimentos, estimulando mudanças nas relações de trabalho e emprego na esfera local. A assimetria nas relações de poder econômico não impediria a reação dos agentes locais, nas possibilidades de seus recursos e nos horizontes de seus valores, às novas regras e condições do sistema internacional. A relação global-local teria, portanto, implicações distintas entre os agentes sociais.

Esse argumento será discutido a partir da análise da presença da planta montadora da General Motors (GM), instalada no ano de 2000 no município de Gravataí, estado do Rio Grande do Sul. Trata-se de uma das maiores fábricas automobilísticas do país - estima-se produção de 240 mil unidades em 2008 - de uma das principais corporações mundiais. A planta experimenta processo de expansão e de realização de novos investimentos apoiados em incentivos financeiros e fiscais, despertando curiosidades sobre os efeitos disso na atividade econômica, na estrutura produtiva e nas relações de trabalho e emprego na esfera local. Neste caso, caberia inquirir sobre essa nova experiência econômica e social: Como se relacionariam, em conjunturas políticas e de mercado particulares, agentes dotados de distintos níveis de recursos e tipos de estratégias e que mudanças sociais disso decorreriam para o âmbito local?

A mobilidade e integração internacional do setor e a consequente constituição de novos espaços industriais - como no caso em estudo - são, sociologicamente, significativas porque, entre outros aspectos, envolvem um novo e complexo feixe de relações entre múltiplos agentes sociais dotados de recursos, interesses, identidades e, por isso, reações distintas: capital nacional e estrangeiro; grandes e pequenas empresas de ramos diversos, tais como metalurgia, mecânica, borracha, couro, têxtil, plásticos, 
combustíveis, siderurgia, serviços de apoio à produção, venda e pós-venda, seguros e outros; trabalhadores de diferentes funções e qualificações; sindicatos de trabalhadores; governos nacionais e subnacionais; centros de pesquisa; associações empresariais; consumidores; bancos e agentes financeiros, nacionais e internacionais, públicos e privados; movimentos ambientalistas e comunitários. O setor torna-se especialmente interessante porque se organiza em termos de oligopólios internacionais que mobilizam complexas e dinâmicas cadeias de fornecimento, em razão de propriedades estruturais, tais como competição global, inovações tecnológicas, complexidade da divisão técnica da produção, necessidade de altos níveis de capital para investimentos e elevada escala de produção para justificar o negócio.

A produção científica sobre as razões da descentralização do setor e a crise de antigas fábricas, como as do ABC paulista, atesta o caráter privilegiado dessa indústria para o conhecimento das transformações recentes no mundo do trabalho e dos impasses e alternativas de desenvolvimento industrial em face das novas relações global-local. Por certo, o desempenho do ABC paulista é uma importante baliza para o conhecimento dessa indústria no Brasil. Entretanto, estudos sobre novos pólos automobilísticos (GARCIA, 2006; NABUCO; NEVES; CARVALHO NETO, 2002; RAMALHO, 2006; RAMALHO; SANTANA, 2006) permitem identificar diferenças entre o "velho" e o "novo" setor automobilístico: por exemplo, o primeiro acha-se em crise, porém, acumula recursos econômicos, sociais e políticos pela antiga presença de montadoras, hoje, em reestruturação; o segundo, encontra-se em expansão, mas opera com conceitos experimentais nos chamados greenfields. O setor automobilístico não poderia mais ser reduzido ao que ocorre no $\mathrm{ABC}$ paulista.

O objetivo central deste artigo seria discutir aspectos das relações global-local, focalizando o processo de formação e desenvolvimento do 
pólo automobilístico de Gravataí e suas implicações sociais no âmbito das relações de trabalho e emprego em empresas locais.

Os dados foram obtidos em entrevistas com gestores da montadora e de empresas fornecedoras locais e com líderes do sindicato metalúrgico local, assim como em diferentes fontes secundárias, apontadas ao longo do texto, como convenções e contratos coletivos de trabalho (CCT) e relatórios da Prefeitura Municipal. As sete empresas locais selecionadas têm distintos níveis e tipos de recursos: Empresa A é um grande fabricante de capital estrangeiro de sistemas de barra homocinética e de eixo dianteiro (I nível da cadeia); Empresa B é um grande fabricante de capital nacional de sistemas de direção e de bombas injetoras de combustível (I nível da cadeia); Empresa C é um pequeno fabricante de capital nacional de usinados de precisão (II nível da cadeia); Empresa D é um médio fabricante de capital nacional de usinados e forjados (II nível da cadeia); Empresa $\mathrm{E}$ é um médio fabricante de capital nacional de componentes de borracha (II nível da cadeia); Empresa F é um médio fabricante, recentemente adquirida pelo capital estrangeiro, de escovas de carvão e porta escovas (II nível da cadeia); e Empresa G é um microfabricante de capital nacional de usinados de baixa precisão (III nível da cadeia). As empresas estão domiciliadas na Região Metropolitana de Porto Alegre (RMPA).

Na seção a seguir, será examinado o processo de constituição do mercado automobilístico global e as estratégias desenvolvidas na planta de Gravataí face ao novo contexto, destacando as relações da montadora com empresas locais. O foco recai sobre processos de interação entre grandes e pequenas empresas face a cenários de globalização. Depois, serão analisadas mudanças sociais na região relacionadas à presença da montadora, tentando evidenciar as relações entre instituições e cadeia produtiva local. A seção seguinte, propõe-se a interpretar a diversidade nas mudanças nas relações de trabalho e emprego, tentando relacioná-las 
com recursos econômicos e sociais disponíveis, e com escolhas dos agentes sociais. Por fim, formulam-se as principais conclusões da análise, buscando suscitar questões ao debate sociológico e identificar pautas sociais relevantes no processo de integração ao sistema global.

\section{Mercados e agentes globais}

Estudos especializados sobre a indústria automobilística (BOYER; FREYSSENET, 2001; CUTCHER-GERSHENFELD et al., 1998; FREYSSENET, 2005; LUNG, 2002, 2006; NELDER; HARRYS; EVENS, 2001) identificam a formação, na segunda metade da década de 1990, de um mercado global nesse setor, distinguido: a) pela saturação dos principais mercados consumidores nos países centrais que estimularia a prospecção de mercados emergentes; b) pela atratividade de novos mercados a partir de acordos comerciais e de blocos regionais como o Mercosul; c) pelo ingresso de novos competidores no mercado mundial mediante fusões e aquisições entre companhias; e d) por vantagens competitivas em regiões de tipo greenfield, com destaque para países emergentes como o Brasil (infraestrutura adequada, mão-de-obra escolarizada e barata, incentivos financeiros e fiscais).

As mudanças nas regras de competição exigiram novas estratégias dos agentes econômicos e sociais. Nos últimos 10 anos, montadoras investem em uma nova geração de fábricas que, apoiadas em referências competitivas globais, são mais flexíveis e produtivas do que antigas plantas, expressando influências das tecnologias da informação e comunicação e de processos globais nessa indústria. O setor automobilístico apresenta, hoje, caráter movediço: tensos processos de reestruturação ou de fechamento de antigas fábricas deflagram a crise de tradicionais regiões industriais, ao passo que plantas inovadoras levam novas referências competitivas a regiões emergentes. A constituição desses novos pólos automo- 
bilísticos, como no caso de Gravataí, cria um novo conjunto de relações entre agentes globais e locais.

O setor automobilístico constitui-se, inegavelmente, em símbolo do desenvolvimento industrial brasileiro. Essa indústria desenvolveu-se, no período entre a década de 1950 até o início dos anos 1990, em condições de relativa proteção e controle pelo poder público, no contexto do modelo de substituição de importações: ampla oferta de subsídios, controle governamental sobre decisões de investimento, proteção e reserva de mercado. Porém, em meados da década de 1990, o setor integra-se ao mercado global, mediante processos de abertura e liberalização do mercado interno, de fusões e aquisições de empresas nacionais de autopeças pelo capital estrangeiro, de entrada de novos concorrentes, de disseminação de tecnologias de informação e comunicação, e de atração de investimentos para novas regiões industriais do país. Isso alterou não apenas a geografia do setor - antes concentrado no estado de São Paulo, hoje com fábricas em diferentes estados e regiões - como também as relações entre os agentes sociais envolvidos - o que se tenta demonstrar neste artigo. É nesse contexto de céleres mudanças econômicas e sociais que a GM instala sua unidade montadora em Gravataí. A planta inscreve-se, como se sabe, em um ciclo de investimentos, estimulado pelo Regime Automotivo de 1995 que, de acordo com Arbix e Zilbovícius (2002), estabeleceu não apenas a rápida abertura e liberalização do mercado nacional como também facilidades financeiras e fiscais para atrair capital estrangeiro para o país.

Chamam a atenção diferenças no comportamento dos agentes globais de acordo com conjunturas políticas, econômicas e setoriais dos países. Em países centrais, a opção das montadoras seria pela produção de modelos de alto valor agregado e conteúdo tecnológico porque existiria maior tradição na produção automotiva, acúmulo de conhecimentos específicos, instituições consolidadas e elevado poder aquisitivo dos consumidores (CUTCHER; 
GERSHENFELD et al., 1998; LUNG, 2002; RUBINSTEIN; KOCHAN, 2001). Em países emergentes, as escolhas tenderiam a ser diferentes. No México, as montadoras optariam pela simples produção em grandes escalas, tendo em vista a exportação para Estados Unidos e Canadá, em decorrência de fatores como estímulo governamental e mão-de-obra barata (CARRILLO, 2001). Na China, as montadoras tenderiam à produção de modelos de baixo custo para atender a demanda interna face às dimensões e à recente e controlada abertura desse mercado (ZHANG, 2005). O Brasil constituiria um mercado favorável a experimentações em termos de desenvolvimento de produtos de baixo custo e de esforços de inovação no processo produtivo - por exemplo, motores 1.0 litros, motores flexfuel, produção em condomínio industrial. Isso decorreria da oferta de incentivos governamentais para novas plantas e da longa trajetória dessa indústria no país que sedimenta fornecedores, mão-de-obra e conhecimentos necessários para projetos inovadores. Porém, instabilidade econômica e carências institucionais dificultariam a criação de modelos de alto valor e conteúdo tecnológico (LUNG, 2006; SALERNO et al., 2004).

Parece que o Brasil integra-se ao mercado automobilístico global de forma mais rápida do que o México, onde a abertura do setor se inicia ainda na década de 1980, e menos regulada do que a China - aqui, por exemplo, estimulou-se a guerra fiscal. Ademais, isso ocorre em conjuntura de estagnação econômica. Tais "particularidades" tenderiam, pois, a reduzir as chances de expansão de empresas locais, de ganhos nos empregos e nos salários, e de relações cooperativas nos elos da cadeia produtiva. De qualquer forma, analistas (ABREU; BEYNON; RAMALHO, 2006) têm insistido no argumento de que novas plantas montadoras instaladas no país constituiriam, hoje, referências sobre um novo tipo de sistema produtivo no setor em âmbito mundial, superando a simples aplicação ou adaptação de modelos industriais. 
No caso de Gravataí, a montadora desenvolve uma fábrica, de fato, inovadora e em expansão, impondo novas referências competitivas e produtivas aos agentes locais, no caso trabalhadores, fornecedores, sindicatos, associações empresariais e governos. Ao investimento inicial de US\$ 600 milhões para a produção do "Celta" (US\$ 350 milhões da GM e US\$250 milhões das 17 sistemistas, com contrapartida do governo estadual e da prefeitura municipal, no contexto de "guerra fiscal"), foram adicionados, nos anos de 2005-2006, US\$ 250 milhões, tendo em vista a montagem, em 2007, do sedan compacto "Primus", ampliando a capacidade da planta de 120 mil para 240 mil unidades ao ano. Segundo gestores da montadora, a planta contava com cerca de 3500 empregados em 2005, passando para cerca de 5350 no ano de 2007. A fábrica é considerada modelo pela direção da montadora: pioneira em vendas via internet no país; robotização 40\% superior à planta de São Caetano do Sul; produtividade de cerca de 100 veículos/empregado/ano - o dobro de outras unidades recém instaladas no Brasil; uso do conceito de condomínio industrial. Ademais, os carros produzidos em Gravataí foram projetados no Brasil. Esse caráter inovador da planta reflete-se, entre outros aspectos, em tendência ao uso de mãode-obra relativamente bem treinada, jovem e escolarizada, embora persistam setores críticos quanto às condições de trabalho. Conforme líderes sindicais, na estação de pintura, operadores realizam, incomunicáveis entre si, tarefas repetitivas ao longo da jornada de trabalho².

Como já referido, o pólo de Gravataí tem a forma de condomínio industrial (uma novidade à época de sua implantação). No primeiro nível da cadeia produtiva, estão, in site, fornecedores de sistemas do veículo - as chamadas "sistemistas" que produzem em tempos paralelos - e prestadores de serviços auxiliares e de apoio à produção, assim como, off site, fornecedores de conjuntos e autopeças. No segundo e terceiro níveis,

2 Análise detalhada do processo e condições de trabalho na fábrica pode ser encontrada em Garcia (2006). 
estão fornecedores de autopeças, insumos, matéria-prima e mão-de-obra para as empresas do primeiro nível da cadeia. Para ingressar na cadeia produtiva, as empresas locais precisam ajustar-se às referências globais trazidas pela montadora porque as mesmas atuavam, até então, predominantemente, nos mercados de veículos pesados e de reposição de peças - algumas já forneciam para montadoras de São Paulo - com satisfatório padrão de qualidade, porém, com limites de escala, custos e prazos de entrega para atender o novo mercado. Gestores da montadora dão conta de que havia 69 fornecedores locais integrados ao complexo no ano de 2000, passando para 492, em 2005. A despeito desse crescimento, as empresas locais representavam apenas $28 \%$ do total de fornecedores da planta. O dado aponta tendência de substituição gradual de fornecedores de outros estados e países por empresas locais, bem como a existência de amplo espaço para a inserção de fornecedores locais na cadeia, à medida que haja a capacitação dos mesmos para o alcance de padrões globais exigidos pela montadora. Isso será retomado adiante no texto.

As "sistemistas" tendem a desenvolver relações apoiadas na divisão de riscos e custos do negócio com a montadora, em troca de exclusividade e de maior valor agregado no fornecimento: aplicação de capital na construção da planta, engenharia conjunta no desenvolvimento dos sistemas, compartilhamento de infraestrutura e de logística, alto grau de coordenação e integração do processo produtivo. Há evidências sobre a transferência de responsabilidades da montadora para suas "sistemistas", requerendo confiança nas relações interfirmas. As "sistemistas" são selecionadas mediante licitação internacional, tratando-se, em geral, de empresas que fornecem para diferentes plantas e montadoras, no país e no exterior. Isso reforça a interdependência entre as empresas. O condomínio opera com número relativamente pequeno de fornecedores diretos de componentes, reduzindo, num primeiro momento, as chances de que 
empresas locais ingressem nos elos mais nobres da cadeia produtiva. Por outro lado, a transferência de sistemas ou de conjuntos de maior valor agregado tende a propagar-se na cadeia, em benefício de empresas locais. Outro aspecto interessante seria a crescente importância dos serviços de apoio à produção, envolvendo amplo contingente de atividades e empresas, como logística, infraestrutura e comunicações.

As empresas locais tendem a conviver com fortes pressões em termos de redução de preços, de elevação nas escalas de produção, de aperto nos prazos de entrega e de constante aperfeiçoamento da qualidade dos produtos. Isso requer investimentos dessas empresas em tecnologia, flexibilidade e capacidade de integração no processo produtivo da montadora. Essa capacitação precisa ser realizada com capital, tecnologia e conhecimentos próprios porque não há programas de desenvolvimento de fornecedores locais, quer da montadora, quer das "sistemistas", representando enormes sacrifícios para empresas com menores níveis de recursos e seus trabalhadores que pagam mais caro para pertencer à cadeia. Nessas circunstâncias, a montadora constitui referência no que se refere aos padrões de produção e de trabalho para a reestruturação nas empresas locais, estimuladas a investir pela escala de compras e pelas possibilidades de aprendizado ao integrar uma cadeia liderada por uma fábrica desse porte.

O que foi exposto indica, portanto, a ocorrência de relações assimétricas entre empresas globais e locais no novo pólo automobilístico, em razão das novas condições de competição no setor em nível mundial, assim como de fatores conjunturais em âmbito nacional e local (incertezas de mercado e atraso tecnológico de fornecedores locais). O grau de mobilidade dos agentes globais permite-lhes condutas impositivas diante dos agentes locais, na busca de vantagens competitivas e baixos custos de produção, deixando de desenvolver fornecedores locais, diferentemente do que ocorria no passado. O novo contexto aumenta a importância da ação institucional em favor de empresas locais. 
Apesar disso, parece verdadeiro dizer que tais relações seriam uma porta para a esfera local ao sistema global, uma vez que podem criar chances de transferência de tecnologias, de aprendizado organizacional e de aquisição de conhecimentos. Ademais, agentes globais podem, como no caso estudado, ampliar escalas de produção e de compras locais, consistindo em fator de estímulo ao investimento e à promoção de novas capacidades na esfera local. Essas externalidades acabariam, em certa medida, gerando enraizamentos, por mais que suas motivações sejam obter vantagens de baixos custos locais. No caso de Gravataí, é preciso notar que se trata de uma grande fábrica, de produtos bem aceitos no mercado e de conceitos e tecnologias inovadores, contribuindo para aqueles resultados econômicos e sociais. Sob outras condições, esses resultados tenderiam a ser diferentes.

\section{Contexto local}

A presença de agentes globais em contextos locais tem implicações sociais e políticas significativas, tanto pelo ingresso de novos recursos econômicos e sociais quanto pela reação dos agentes locais ao novo contexto e às novas regras. Os resultados obtidos na experiência de Gravataí aproximam-se de estudos sobre o pólo automotivo do Sul Fluminense (RAMALHO; SANTANA, 2006) que têm identificado não somente reações de sindicatos locais inclusive greves e paralisações de que resultariam conquistas em negociações salariais - como também certo "acúmulo de relações políticas" nessas regiões, favorecendo a criação de novas pautas - como atração de investimentos e formação profissional - e esforços de participação sindical em espaços públicos regionais. Isso contraria argumentos correntes (MELLO-E-SILVA, 2006) de que o paradigma da produção flexível implicaria em exclusão política dos trabalhadores e de seus sindicatos do debate sobre o mundo do trabalho, dominado pela unilateralidade do poder gerencial. 
Como já referido, observa-se um novo dinamismo na atividade produtiva do município de Gravataí e no setor metal-mecânico em municípios vizinhos (Cachoeirinha, Canoas, Novo Hamburgo e São Leopoldo), após a instalação da planta montadora. Os reflexos da presença do pólo de Gravataí já são sentidos a partir de 1998, quando se inicia a construção do complexo, e tornam-se mais contundentes, a partir do ano 2000, quando a montadora entra em operação. Os dados são expressivos: em Gravataí, o total de alvarás concedidos pelo município para a instalação de novas empresas cresceu 26,4\% no período de 1997 a 2003 (de 23.803 para 30.079 alvarás). A expansão do nível de emprego formal foi de 43,2\% no mesmo período (de 23.462 para 33.600 empregos). O aquecimento da atividade econômica e industrial reflete-se, também, na expansão de 123\% no PIB entre 1997 e 2002 (de R \$ 1,3 bilhão para R \$ 2,9 bilhões) e de 209\% na receita tributária entre 1997 e 2004 (de R\$ 22 milhões para $\mathrm{R} \$ 69$ milhões) (Dados obtidos junto à Prefeitura de Gravataí e à Fundação de Economia e Estatística do Rio Grande do Sul). Além disso, a cidade passa a receber novos investimentos de empresas direta e indiretamente relacionadas ao pólo automobilístico, por exemplo: ampliação da Pirelli e da Johnson Controls, nova fábrica da Arteb, hipermercados, empreendimentos imobiliários, hotéis e restaurantes, novas instituições privadas de ensino, e ampliação e modernização do hospital local.

O ingresso de novos recursos e as pressões competitivas impostas pela montadora mobilizam instituições locais, no esforço de obter benefícios. Os sindicatos locais pactuam um contrato coletivo de trabalho válido para a GM e suas sistemistas e convenções coletivas de trabalho para as empresas metal-mecânicas locais. Essa fragmentação das negociações reflete-se em diferentes níveis salariais e condições de trabalho e emprego ao longo da cadeia produtiva (montadora, sistemistas, empresas locais), constituindo, como apontam Lee e Frenkel (2004), nova dificuldade para 
a ação sindical no contexto de sistemas de produção flexível. No entanto, certas conquistas dos sindicatos tendem a beneficiar o conjunto da cadeia. As negociações de reajustes salariais para trabalhadores da GM, sistemistas e empresas locais de Gravataí acumulam 41\%, no período de maio de 2000 até setembro de 2003, acima dos índices de inflação no período (INPC: 29,45\%; IPCA: 26,17\%). Para os trabalhadores de empresas locais de Porto Alegre, o reajuste totalizou, a juros compostos, 34,8\%, no período (também acima dos índices de inflação). Tal diferença de resultados poderia ser atribuída ao crescimento recente do setor, mais consistente em Gravataí do que em Porto Alegre. Outro fator a considerar seriam as estratégias de ação dos sindicatos, mais próxima da ideia de colaboração em Gravataí (Força Sindical) e mais próxima da ideia de confronto no caso de Porto Alegre (Cut). Os sindicatos têm enormes dificuldades de ação no interior da fábrica face ao desequilíbrio de forças perante agentes globais. Porém, os mesmos têm sido capazes de mobilizar greves e paralisações em torno de conflitos sobre banco de horas, abonos, participação nos resultados, transporte e demissões. Ao mesmo tempo, buscam, em meio às dificuldades, participar em espaços públicos e interferir em aspectos da vida da população trabalhadora, fora da fábrica, contribuindo para pôr demandas trabalhistas na agenda pública.

As associações empresariais também têm reagido à presença de agentes globais. Em 1998, foi criado o Instituto Gaúcho de Estudos Automotivos (Igea), vinculado à Federação das Indústrias do Estado do Rio Grande do Sul (FIERGS). Trata-se de uma associação empresarial aplicada à promoção do desenvolvimento do setor automotivo no Estado, contando, em 2005, com 107 empresas associadas, 30 participantes nos grupos de trabalho, e 15 projetos em andamento em apoio às empresas do setor. Entretanto, o Instituto pouco tem contribuído com pequenas e microempresas do setor, mais carentes de recursos e com maiores dificuldades para atender padrões 
globais de fornecimento ${ }^{3}$. A Associação Comercial e Industrial de Gravataí (Acigra) cria, em 2004, um núcleo que integra empresas metal-mecânicas da região, tendo em vista discutir e encaminhar demandas do setor.

No que se refere ao poder público, a ação governamental foi decisiva na atração da montadora e sistemistas, mediante a concessão de amplos benefícios em contexto de "guerra fiscal". Com relação às empresas locais, as estratégias têm sido reformuladas no sentido de atender demandas desses agentes face à escassez de recursos e às carências institucionais. A insuficiência dos instrumentos de crédito de caráter genérico (não se aplicam especificamente ao setor metal-mecânico), como o Fundopem/RS (utilizado pela GM, por exemplo) ${ }^{4}$, o Finame Automático/BNDES e o BNDES Automático, que não atingiram as necessidades das pequenas empresas locais, têm sido parcialmente enfrentadas com a reformulação e criação de programas para o setor. O Caixa RS, instituído em 2004, inicialmente também de caráter genérico, foi modificado pelo governo estadual, em 2005, com a oferta de uma linha de crédito específica para o setor no Estado: o Prodeauto (Programa de Desenvolvimento das Empresas de Autopeças) ${ }^{5}$. Outra novidade foi a criação, em novembro de

\footnotetext{
3 Um dos projetos é o Sistema GDC (Gestão Dinâmica da Cadeia Automotiva do RS), no âmbito do Programa de Cooperação Científica e Tecnológica para o Desenvolvimento Regional/ Arranjos Produtivos Locais da FINEP - Financiadora de Estudos e Projetos. Consiste em um banco de dados relacional de alto nível, com alimentação dinâmica e atualizada de dados, os quais permitem gerar informações a respeito dos principais indicadores da cadeia automotiva e de seus elos, prospectando as principais tendências tecnológicas e mercadológicas ocorridas no plano nacional e internacional. O GDC, no entanto, é de uso exclusivo dos sócios do IGEA. Outro programa é o de Gestão, voltado para aferir a qualidade dos sistemas produtivos e a obtenção de certificação pelas pequenas e médias empresas.

4 Fundo Operação Empresa do Estado do Rio Grande do Sul, criado em 1972, e alterado em 1997, 1999 e 2003. Trata-se de um programa de incentivo para a ampliação, modernização e implantação de indústrias no Estado, tendo em vista a geração de emprego e a melhoria tecnológica e ambiental.

5 O Prodeauto resulta de uma aliança entre a Caixa RS e o Igea, com apoio do Senai, disponibilizando recursos próprios e captados junto ao BNDES para empresas gaúchas que compõem a cadeia automotiva (em 2005, havia disponibilidade operacional de R 437 milhões). A meta
} 
2004, da Agência de Desenvolvimento de Gravataí (ADGR), constituída de representantes governamentais, empresariais, sindicais e acadêmicos em âmbito municipal. Além disso, cabe referir a criação, no ano de 2004, do Conselho Municipal de Desenvolvimento (Comude), que reúne prefeitura, representantes de organizações sociais e empresariais ${ }^{6}$.

As entrevistas em empresas locais revelam limites da ação das instituições locais na promoção de capacidades e da expansão dessas empresas, tendo em vista alcançar padrões globais. Embora ações governamentais estejam em mudança, mostram-se, ainda, isoladas e seletivas. Ademais, os vínculos institucionais empresariais são também limitados: programas de qualidade, ação coletiva, treinamento e formação de mão-de-obra, desenvolvimento de novas tecnologias, parceria com universidades, estão, em geral, ausentes da realidade das empresas locais. O cotejamento do que ocorre na Empresa A e na Empresa B ilustra o argumento acima. A Empresa A, de capital estrangeiro e a maior empresa entre as pesquisadas, foi precisamente a única a beneficiar-se do Fundopem/RS para aprimorar o processo produtivo. Contou, também, com vantagens fiscais do governo municipal onde instalou nova planta. Mantém vínculos com o Igea/ FIERGS e com o sindicato patronal. A Empresa B, de capital nacional, realiza novos investimentos com recursos próprios, mesmo participando ativamente do Igea/FIERGS e do sindicato patronal. Outra evidência da importância do papel das instituições locais e dos seus limites é o que

do programa é elevar de $28 \%$ para $50 \%$ a participação de fornecedores gaúchos nas compras de montadoras instaladas no Rio Grande do Sul. O público-alvo são empresas de qualquer porte, cadastradas no Igea e, preferencialmente, indicadas pelas montadoras como fornecedores efetivos ou potenciais, para as quais são financiados investimentos na expansão da capacidade de produção e em inovação tecnológica, tendo em vista a melhoria da qualidade e da produtividade do processo produtivo.

6 Outro aspecto interessante é a projeção eleitoral que líderes políticos locais vêm alcançando. Em 2006, cinco deputados ligados a Gravataí foram eleitos por diferentes partidos, superando os três parlamentares eleitos no pleito anterior. Em 1998, nenhuma vaga havia sido conquistada por candidato identificado com o município. 
ocorre na Empresa E. O crédito para investimento em novas tecnologias foi obtido no exterior junto ao fabricante, após tentativas sem sucesso no país. Por outro lado, a parceria com um centro tecnológico permitiu à empresa a melhoria significativa da qualidade do processo produtivo, atingindo os padrões globais da montadora e capacitando-a a exportar.

Desse modo, parece haver um novo ânimo institucional na esfera local, que atinge um novo patamar de recursos econômicos e sociais e, ao mesmo tempo, acha-se acossada por novas pressões e demandas com a presença de agentes globais, demarcando um novo contexto de ação. Como atestam os dados acima, ocorrem alterações importantes nas relações e no papel dos agentes em face da mudança de regras do sistema internacional. A competição e as tecnologias da informação e comunicação levam a novos conceitos industriais que aumentam as responsabilidades de fornecedores e que entrelaçam grandes e pequenas empresas na cadeia produtiva. Governos subnacionais antes secundários passam a desempenhar papel importante na relação com montadoras: incentivos, esforços de capacitação da cadeia produtiva local, infraestrutura urbana, estímulo às exportações, esboço de estratégias de desenvolvimento regional. Associações empresariais e centros de pesquisa são demandados no auxílio à reestruturação de empresas locais face aos requisitos competitivos globais das montadoras. Sindicatos locais acham-se pressionados pela força e pelo complexo jogo de relações trazidas pelas montadoras e seus fornecedores estrangeiros - em contexto de crise mundial nas taxas de filiação - e tentam buscar novos espaços de ação.

\section{Agentes locais}

A apreciação da presença da GM em Gravataí mostra que esta vem estimulando mudanças sociais nas empresas locais investigadas. No entanto, 
os distintos níveis de recursos sociais - capital, produto e tecnologia, informação e acesso a mercados, qualificação da mão-de-obra - e estratégias competitivas - agregação de valor ao produto, elevação da competitividade e da produtividade, flexibilização do trabalho e do emprego -, em contexto de carências das instituições locais e de imposições da montadora, refletem-se em diferentes fases no processo de flexibilização das relações de trabalho e emprego. Tal constatação reforça argumentos de estudos internacionais sobre o setor de que plantas montadoras no contexto de competição do mercado global instituiriam um novo modelo de competências que se disseminaria na rede de fornecedores (DURAND, 2002), assim como tenderiam a estimular diferentes condições de emprego e trabalho ao longo da cadeia automotiva (LEE; FRENKEL, 2004; SALLAZ, 2004; ZHANG, 2005).

As empresas em etapa mais avançada de reestruturação e de flexibilização das relações de trabalho e emprego parecem deter os maiores níveis de recursos dentre os casos investigados. A Empresa A, de grande porte e capital estrangeiro, produz sistemas de suspensão de alta tecnologia para diferentes montadoras. Com algum apoio institucional, realiza investimentos em expansão da planta e aprofunda processos de reestruturação, bem como experimenta significativa expansão do faturamento e da produtividade (a empresa faturou R \$ 192 milhões em 1999 e R \$ 400 milhões em 2003). Neste caso, eleva-se o emprego na empresa (entre 1999 e 2003, cresce de 1.100 para 1.500 postos diretos) e há certos ganhos para os trabalhadores (PLR, benefícios sociais, treinamento, maiores chances de participação, estabilização da mão-de-obra no emprego). O percentual de mulheres empregadas atinge $20 \%$, acima da média do setor que é $12 \%$. Entretanto, crescem as pressões sobre os trabalhadores, em termos de metas de desempenho e de responsabilidades com o trabalho. 
A Empresa B, de grande porte e capital nacional, fabrica sistemas de direção e de bombas injetoras, para exportação e para outras montadoras no país. Com apoio institucional menos significativo do que a empresa A, expande-se (faturamento passou de R \$ 88 milhões em 1999 para $R \$$ 163 milhões em 2003) com uma estratégia de investimento em novas tecnologias e em agregação de valor ao produto, utilizando-se de capital próprio. Os principais reflexos para os trabalhadores seriam a seletividade da oferta de treinamento aos trabalhadores, uso de trabalho temporário, uso de regime de compensação de horário, ampliação das pressões por produtividade e retração do emprego (de 800 postos em 1999 para 614, em 2003) ${ }^{7}$. Contudo, houve importantes ganhos nos reajustes salariais e na PLR. A empresa $B$, com menor acesso às instituições locais e de capital nacional, revela processo de flexibilização das relações de trabalho e de emprego mais restritivo com os trabalhadores do que na Empresa A.

Outras empresas acham-se em pleno processo de reestruturação e de flexibilização das relações de trabalho e de emprego, situando-se em etapa anterior comparativamente aos casos das empresas A e B. Na Empresa $\mathrm{D}$, constata-se a reestruturação do processo produtivo, com ênfase na agregação de valor ao produto, paralelamente a um lento movimento de flexibilização das relações de trabalho e de emprego. Há expressiva expansão do faturamento: R\$ 23 milhões em 1999; R\$ 74 milhões em 2003. É uma média empresa que produz conjuntos de usinados e forjados (menos especializados do que as empresas A e B) e que atuava no mercado nacional de montadoras de veículos pesados, passando a exportar, após sua integração à cadeia liderada pela GM em Gravataí. As pressões da cadeia sobre a empresa exigiram a reestruturação do processo produtivo para a qual conta com financiamento do BNDES. Isso requereu mão-de-obra mais instruída e treinada, oferecendo-se maiores chances

7 Segundo um jornal local, a empresa B teria atingido 1000 empregos no ano de 2007. 
de promoção e de intervenção dos trabalhadores no processo de trabalho assim como maiores salários. Por outro lado, as relações de emprego tornam-se segmentadas face a demissões e ao uso do trabalho temporário: passa de 400 empregados diretos em 1999 para 370, em 2003.

A Empresa $\mathrm{E}$, de pequeno porte, produz componentes de borracha. Conta com vínculos institucionais relativamente amplos, considerando-se os casos investigados. O fornecimento ao novo pólo automobilístico de Gravataí, no II nível, implicou a expansão da empresa (em 1999, faturou R 4 milhões e empregou 80 trabalhadores; em 2003, faturou R\$ 10 milhões e empregou 107 trabalhadores), investimentos significativos em inovação tecnológica, aprimoramento da qualidade e diversificação da linha de produtos. Passa a exportar e a produzir para outros complexos automotivos. Modificase o processo produtivo, passando a se tornar central a participação dos trabalhadores, em termos de controle e de aprimoramento da produção. Neste caso, exige-se mão-de-obra mais instruída e treinada, e mais comprometida com os resultados da empresa. Os trabalhadores obtêm chances de intervenção no processo produtivo, de estabilização no emprego, de promoção da segurança no trabalho e vêem valorizadas a formação técnica e a escolaridade. Um achado neste caso foi a instituição da PLR a parte dos trabalhadores. A PLR é aplicada aos operadores de novas tecnologias, as chamadas "injetoras", em detrimento dos operadores de tecnologias tradicionais, as chamadas "prensas". Outro aspecto relevante sobre a nova tecnologia seria a criação de chances de emprego para mulheres, que foram empregadas por certo período. Posteriormente, a gerência julgou inadequada a permanência de mulheres em "setores masculinos" da fábrica.

A Empresa F, de porte médio e de capital estrangeiro, produz escovas de carvão e porta-escovas para o mercado nacional. Embora com escassos vínculos institucionais, eleva a competitividade externa, decorrente de um processo de rebaixamento de custos e de preços e de melhoria da qualida- 
de, apresentando expansão do faturamento (de R \$ 15 milhões para R \$ 21 milhões, no período de 1999 a 2003) e do emprego (de 210 para 300 trabalhadores, no período de 1999 a 2003). As mudanças relativas ao conteúdo do trabalho são relativamente limitadas: o uso do trabalho em equipe, por exemplo, ainda não é generalizado na fábrica. As relações de trabalho e de emprego apresentam lentas mudanças: crescimento do emprego, elevação da instrução e das oportunidades de trabalho feminino, introdução da PPR, estabilização da mão-de-obra. Os ganhos na remuneração referem-se aos reajustes previstos em CCT e à PPR.

Como se observa, as empresas $\mathrm{D}, \mathrm{E}$ e $\mathrm{F}$ detém menores recursos do que as empresas $\mathrm{A}$ e $\mathrm{B}$, o que, em contexto de timidez institucional e de ausência de programas de desenvolvimento de fornecedores pela montadora, tende a reduzir a profundidade e a tornar mais lentos os processos de ajuste dessas empresas às referências globais.

Há, também, empresas que recém ingressam nos processos de reestruturação e de flexibilização das relações de trabalho e de emprego ou que mantêm formas rígidas de organização do trabalho. A Empresa $\mathrm{C}$ detém menores recursos do que as empresas antes mencionadas: pequena empresa de capital nacional, produz subsistemas de usinados e atua no mercado local. Conta com escassos vínculos institucionais, dificultando sua trajetória de capacitação. Há expansão da empresa, conjugada com reestruturação do processo produtivo -introdução de novo plano de cargos, certificados de qualidade, formas participativas no trabalho, implementação de regimes de metas -, refletindo-se em criação de empregos (de 20 para 50 postos, no período de 1999 a 2003) e em chances de promoção e participação da mão-de-obra no processo produtivo, porém, trabalhadores considerados obsoletos deverão ser descartados. A escolaridade torna-se crucial nessa dinâmica de seletividade. As relações de trabalho e de emprego vêm assumindo formas mais flexíveis e instáveis na empresa. 
Por fim, a empresa G - microempresa, produtora de peças usinadas simples e em pequena escala, situada no III nível da cadeia e com os menores vínculos institucionais - revela a permanência de práticas organizacionais rígidas e do emprego de tecnologias convencionais. Houve expansão do negócio (faturou R\$ 20 mil em 1999 e R\$ 50 mil em 2003), porém, o conteúdo do trabalho não sofre alterações significativas. A empresa não apresenta mudanças nas relações de trabalho e de emprego e mantêm os mesmos quatro postos de trabalho.

Pode-se, pois, concluir que as respostas dos agentes locais ao sistema global relacionam-se com os seus recursos e estratégias. Quanto maiores os níveis de recursos e mais a empresa local os utilizar na agregação de valor ao produto e na inovação (produzir sistemas), tanto maiores seriam as chances dos trabalhadores extraírem vantagens nos processos de flexibilização das relações de trabalho e de emprego. Porém, empresas locais com níveis de recursos mais baixos tenderiam a se valer de processos mais duros de flexibilização das relações de trabalho e de emprego.

O caso estudado aponta realidades sociais híbridas, contraditórias, diversificadas e em rápida transformação. No conjunto das empresas, há mudanças positivas, tais como expansão de atividades em diferentes níveis da cadeia produtiva, elevação geral do nível de emprego e ganhos salariais. Os esforços empresariais de agregação de valor e de investimento em novas tecnologias propiciam ganhos em termos de qualificação dos trabalhadores e de oportunidades de intervenção dos mesmos no processo produtivo. Porém, trabalhadores de toda a cadeia tenderiam a conviver com ritmo de trabalho mais intenso e com novas responsabilidades face aos dramáticos regimes de metas, ao trabalho em equipe, à polivalência, às demandas por participação e solução de problemas. Ademais, a diversidade de práticas e condições de emprego e trabalho cria novas dificuldades para a atividade dos sindicatos. 


\section{Conclusões}

Com base nas indicações acima apresentadas, pode-se perceber a complexidade e as transversalidades envolvidas na questão das relações global-local que implicam desafios para pesquisa e novas pautas e lutas sociais.

A constituição de um mercado global imporia novas referências competitivas aos contextos locais, mediante relações, inequivocamente, desiguais entre os agentes sociais. No entanto, a configuração desses novos espaços industriais dependeria das escolhas dos agentes no uso dos recursos disponíveis e na prospecção de vantagens e de possibilidades decorrentes das novas regras do sistema internacional. O caso em discussão é emblemático. As adversidades não paralisaram os agentes locais: empresas, associações, sindicatos e governos. Ao contrário, verificam-se rápidas transformações na esfera local assim como a busca de benefícios das novas relações que se estabelecem. Os agentes sociais reorientamse, fazendo escolhas na preservação de seus interesses e valores. Quanto maior o nível de recursos do agente, tanto mais possibilidades de escolha.

Essa conclusão suscita a candente questão, brevemente referida na análise do caso acima, sobre as relações entre identidades, ideologias e tradições locais, e processos de desenvolvimento industrial. Seriam necessários novos estudos não apenas sobre como se transformam valores e crenças no processo de integração ao sistema global, mas também aprofundando como elas interferem nas escolhas dos agentes, considerandose as particularidades e a diversidade da sociedade brasileira.

Finalmente, caberia referir que o debate e as lutas sociais em torno da cidadania no mundo do trabalho tenderiam a assumir novos contornos face ao sistema global. Esboçam-se a seguir pontos críticos identificados a partir da análise sociológica das relações global-local:

Primeiro, independente dos níveis de recursos das empresas, o ritmo de trabalho tenderia a intensificar-se, afetando todos os grupos de 
trabalhadores. Isso suscita o debate sobre a jornada de trabalho e sobre maior controle pelo trabalhador do tempo de trabalho. Esse aspecto precisaria ser posto mais nitidamente pelos agentes sociais na agenda pública face as suas conseqüências sociais.

Segundo, outro tema emergente seria sobre novos caminhos para a democracia no trabalho e para as estratégias de ação sindical, tendo em vista a ampliação da participação de trabalhadores e o seu reconhecimento pelas empresas como interlocutor legítimo na esfera do trabalho. A presença sindical nos locais de trabalho tem sido difícil, em razão da adoção de instrumentos organizacionais adversos aos sindicatos, da força dos agentes globais e da conjuntura de elevado desemprego. Contudo, os sindicatos parecem despertar para estratégias de difusão e de fortalecimento de comissões de fábrica, a partir de temas emergentes, como remuneração variável e jornada flexível. Outro caminho profícuo das estratégias sindicais parece ser a busca pela presença em novos espaços públicos, tendo em vista a discussão de diferentes aspectos do desenvolvimento local e a contribuição para melhores condições de vida na comunidade e na esfera do trabalho.

Terceiro, condições de competição global tenderiam a aumentar a seletividade e a diversidade das condições de emprego e de trabalho na cadeia produtiva. A ampliação de benefícios para a esfera local requereria mudança de valores do empresariado local, tais como a percepção do seu papel em ações coletivas e a conjugação de esforços com outros agentes na negociação de contrapartidas diante da presença de agentes globais. Os benefícios do estabelecimento de relações global-local poderão ser potencializados com o investimento em ações institucionais, indispensáveis para o crescimento coletivo.

Quarto, os agentes locais precisarão elaborar alternativas de desenvolvimento regional, evitando uma possível dependência em relação ao desempenho da planta montadora. Sabe-se que investimentos automo- 
bilísticos têm um ciclo de vida, ocorrendo crises, queda de performance e, em algum momento, o seu esgotamento. A esfera local deverá explorar a nova complexidade adquirida pela atividade produtiva e pelo mercado de trabalho na região, tendo em vista atrair investimentos e estimular funções, conhecimentos e setores emergentes. A presença de um agente global deve ser explorada na promoção de diversidade econômica e social no âmbito local.

Essas poderiam ser pautas capazes de contribuir para a conquista de novos patamares de cidadania no trabalho e de benefícios coletivos, no contexto do sistema global.

\section{Global agents and the local level: the Gravataí automotive complex}

\section{Abstract}

This article discusses aspects of the global-local relations, focusing on the process of formation and development of the Gravataí automotive complex and its social implications as related to the labor relations and employment in local companies. In accordance with the recent formation of the global system, it is assumed that the presence of global agents in local contexts creates new social dynamics that depend on specific arrangements between economic and institutional circumstances, levels and types of available social and economic resources, and strategies mobilized by social agents. The global agents would impose new competitive and technological references to the local agents, who would often be unprepared to meet such requirements. On the other hand, there could be alternative ways of providing access to capital, markets, technologies and knowledge, encouraging changes in labor relations and employment at the local level. The asymmetry in the relations of economic power would not prevent the local agents from reacting to the new rules and conditions of the international system, in accordance with the possibilities offered by their resources and the limits of their values. Thus, the global-local relation would have different implications among the social agents. 
Keywords: Automotive industry. Labor relations and employment. Supply chain. Regional development. Globalization.

\section{Referências}

ABREU, A.; BEYNON, H.; RAMALHO, J. R.. A fábrica dos sonhos da Volkswagen. In: RAMALHO, J. R.; SANTANA, M. A. (Orgs.). Trabalho e desenvolvimento regional - efeitos sociais da implantação do pólo automotivo Sul Fluminense. Rio de Janeiro: Mauad X, 2006. p.71-90.

ARBIX, Glauco; ZILBOVÍCIUS, Mauro. Ajuste local à globalização: um estudo comparativo do investimento estrangeiro direto no ABC e na Grande Porto Alegre. Genebra: OIT, 2002.

ARRIGHI, Giovanni. A ilusão do desenvolvimento. 3 ed. Petrópolis: Vozes, 1997. BECK, Ulrich. O que é globalização? Equívocos do globalismo, respostas à globalização. São Paulo: Paz e Terra, 1999.

BOYER, Robert; FREYSSENET, Michel. Les uns fusionnent, les autres pas. La variete des strategies de profit et des modeles productifs a l'ere de la mondialisation. In: $9^{\text {th }}$ Gerpisa International Colloquium. Paris: Gerpisa, 2001.

CARRILLO, Jorge. TNC'S autoparts in México and development local firms. In: $9^{\text {th }}$ Gerpisa International Colloquium. Paris: Gerpisa, 2001.

CUTCHER-GERSHENFELD, Joel et al. Knowledge-driven work: unexpected lessons from japonese and United States works practices. New York: Oxford University Press, 1998.

DURAND, Jean-Pierre. Main labor changes in French car industry. In: XV World Congress of Sociology. Brisbane: ISA, 2002.

ERNST, Dieter; KIM, Linsu. Global production networks, knowledge diffusion, and local capability formation. Research Policy, n. 31, p. 1417-1429, 2002.

FREYSSENET, Michel. Trajectoires nationales et trajectoires de firmes: esquisse $d^{\prime}$ un schéma $d^{\prime}$ analyse. In: $\mathbf{1 3}^{\text {th }}$ Gerpisa International Colloquium. Paris: Gerpisa, 2005.

GARCIA, Sandro Ruduit. Global e local: o novo pólo automobilístico de Gravataí e suas implicações sociais e políticas. Tese de Doutorado em Sociologia. Volumes I e II. Porto Alegre: PPGS/UFRGS, 2006. 386p.

HARRISON, Lawrence; HUNTINGTON, Samuel (Orgs.). A cultura importa: os valores que definem o progresso humano. Rio de Janeiro: Record, 2002. 
HUMPHREY, John. Opportunities for SMEs in developing countries to upgrade in a global economy. University of Sussex, December, 2001. (Working paper).

LEE, Byoung-Hoon; FRENKEL, Stephen J.. Divided workers: social relations between contract and regular workers in a Korean auto company. Work, employment and society, Cambridge, v. 18, n. 3, p. 507-529, september, 2004.

LUNG, Yannick. La nouvelle geographie du sisteme automobile europeen. In: $\mathbf{1 0}^{\text {th }}$ Gerpisa International Colloquium. Paris: Gerpisa, 2002.

LUNG, Yannick. Le Mercosur dans les trajectoires d'internationalisation des firmes automobiles. Groupement de Recherches Economiques et Sociales, Université Montesquieu-Bordeaux IV, Cahier no.2006-03, janvier, 2006.

MELLO-E-SILVA, Leonardo. Trabalho e sociabilidade privada: a exclusão do outro. Um olhar a partir das células de produção. Revista Brasileira de Ciências Sociais, São Paulo, v.21, n.61, p.147-161, junho de 2006.

NABUCO, M. R.; NEVES, M. de A..; CARVALHO NETO, A. M. (Orgs.). Indústria automotiva: a nova geografia do setor produtivo. Rio de Janeiro: DP\&A, 2002.

NELDER, G. HARRYS, K.; EVENS, L.. The impact on UK regions of reconfiguration in the automotive industry. In: $9^{\text {th }}$ Gerpisa International Colloquium. Paris: Gerpisa, 2001.

RAMALHO, José Ricardo (Org.). Novos espaços industriais e desenvolvimento regional (Dossiê). Cadernos do CRH, Salvador, v. 19, n. 46, 2006.

RAMALHO, J. R.; SANTANA, M. A. (Orgs.). Trabalho e desenvolvimento regional - efeitos sociais da implantação do pólo automotivo Sul Fluminense. Rio de Janeiro: Mauad X, 2006.

RUBINSTEIN, Saul A.; KOCHAN, Thomas A. Learning from Saturn: possibilities for corporate governance and employee relations. Ithaca: Cornell University Press, 2001.

SALERNO, Mário S. et al. Política industrial em setores dominados por transnacionais: o Brasil como sede de concepção e projeto de produto. In: FLEURY, M. T.; FLEURY, A. (Orgs.). Política industrial 2. São Paulo: Publifolha, 2004. p. 67-91.

SALLAZ, Jeffrey J. Manufacturing concessions: attritionary outsourcing at General Motor's Lordstown, USA assembly plant. Work, employment and society, Cambridge, 18:4, p. 687-708, December, 2004.

SCHMITZ, Hubert. Local upgrading in global chains. Estudo Temáticos - Nota técnica 6. Rio de Janeiro, IE/UFRJ-BNDES-FINEP-FUJB, dez., 2000.

STORPER, Michael; CHEN, Yun-chung; PAOLIS, Fernando de. The effects of globalization on the location of industries in the OCDE and European Union. $S / L$, fev., 2000. (Working Paper). 
THERBORN, Göran. Globalizations: dimensions, historical waves, regional effects, normative governance. International Sociology, London, v. 15, n. 2, p. 151-179, jun., 2000.

WALLERSTEIN, Immanuel. Globalization or the age of transition? A long-term view of the trajectory of the world system. International Sociology, London, v. 15, n. 2, p. 249-265, jun. 2000.

ZHANG, Lu. Globalization, market reform and changing labor politics in China's automobile industry. Actes du Gerpisa, Paris, n. 40, p. 41-52, 2005.

Recebido: 03/09/2007

Aceite final: 01/10/2007 